\title{
Deformation Characteristics of Soft Marine Soil Tested under Cyclic Loading with Low Frequency
}

\author{
Yu Lu, ${ }^{1}$ Wenbin Fu ${ }^{D},{ }^{2}$ and Danxuan $X u e^{3}$ \\ ${ }^{1}$ Department of Geotechnical Engineering, College of Civil Engineering, Tongji University, Shanghai 200092, China \\ ${ }^{2}$ Beijing Urban Construction Exploration and Surveying Design Research Institute Co., Ltd., Beijing 100101, China \\ ${ }^{3}$ North China Municipal Engineering Design and Research Institute Co., Ltd., Tianjin 300074, China
}

Correspondence should be addressed to Wenbin Fu; wenbinfu82@163.com

Received 27 July 2020; Revised 25 September 2020; Accepted 30 September 2020; Published 17 October 2020

Academic Editor: Flavio Stochino

Copyright $(2020 \mathrm{Yu} \mathrm{Lu}$ et al. This is an open access article distributed under the Creative Commons Attribution License, which permits unrestricted use, distribution, and reproduction in any medium, provided the original work is properly cited.

\begin{abstract}
Soft marine soil which could be found widely at the coastal and offshore areas is usually associated with high settlement and instability, especially under cyclic loading. Many research studies have been conducted on its deformation characteristics under the cyclic loading with high frequency, whereas few works have been reported on that under the low-frequency cyclic loading which largely existed in engineering. In this work, a comprehensive series of undrained triaxial tests under cyclic loading with low frequency was conducted to investigate the deformation characteristics of soft marine soil. The results demonstrate that soil specimens accumulate plastic deformation and pore pressure under cyclic loading. Specimens tested under conditions such as high confining stress, high-stress ratio, and long cyclic period generally reveal higher deformation and pore pressure. Meanwhile, the rectangular wave presents the largest contribution to plastic strain and pore pressure, followed by the trapezoidal and triangular waves, respectively, whereas the difference between the various waves decreased gradually with the increasing load level and cyclic period. The undisturbed specimens displayed lower deformations and pore pressures than the reconstructed specimens, whereas the differences are not significant when the confining stress is much higher than the structural yield stress. Furthermore, an empirical model for predicting the evolution of pore pressure is proposed and then validated against the experimental data in both this work and the literature.
\end{abstract}

\section{Introduction}

Soft marine soil largely existed at the coastal corridors, low lands, and offshore areas as well as other parts of the earth. This type of soil usually has a high void ratio, significant compressibility, high water content, low permeability, high structural effects, and notable sensitivity. In this marine environment, the foundation design of nearshore and offshore structures is typically governed by the bearing capacity and serviceability under cyclic loadings [1-4], as the cyclic loading could induce reductions of strength $[5,6]$ and bearing capacity $[7,8]$, unexpected settlement $[3,9]$, and other geotechnical engineering problems $[10,11]$.

Investigations on soil behaviour under cyclic loading have been conducted by many researchers, and the variations of cyclic axial strain and pore pressure have been studied through a series of laboratory tests. Common results have confirmed that the deformation and pore pressure characteristics of soft marine soil are strongly dependent on two aspects (i.e., soil properties, such as minerals, structure, porosity, OCR, and loading parameters, such as stress ratio, frequency, and loading history) [12-17]. Since Sangrey et al.'s study [18], researchers begin to notice that the cyclic deformation response of soft marine soil is greatly influenced by the significant increase in pore pressure due to its low permeability compared with that of sands $[19,20]$. Tang et al. [7] analysed the variation of cyclic deformation and pore pressure with increasing stress ratio and cyclic number of mucky clays in Shanghai and stated that it generates greater recoverable elastic strain, accumulated plastic strain, and residual pore pressure when subjected to the cyclic loading with lower frequency under the same stress level in 
the frequency section of $0.5-2.5 \mathrm{~Hz}$. Gu et al. [21] studied the undrained cyclic behaviour of saturated Wenzhou clays and found that the cyclic response of the specimens is strongly influenced by the variation of confining stress, in terms of pore pressure, development speed of cyclic deformation, and magnitude of cyclic strength, which is more appropriate for the simulation of in situ stress fields than the conventional cyclic triaxial tests with a constant confining pressure. Meanwhile, a series of empirical models, including power models [22-24] and hyperbolic models [25-27], have been widely used in the literature for pore pressure prediction. These excellent studies provide fundamental tools for further understanding the cyclic behaviours of soft soils, which is of significance in practical design methods for the stability of nearshore and offshore structures.

However, some of the conclusions in the literature are controversial or have strict application conditions. For example, for the influence of loading frequency, some existing works have indicated that both the accumulated deformation and pore pressure induced by cyclic loading increase with decreasing frequency $[7,20,28]$, whereas other researchers have reported that the frequency has little or no influence on the cyclic deformation and pore pressure $[29,30]$. Actually, soft soil behaviour under undrained cyclic loading is complex for time- and rate-dependent characteristics [6].

Furthermore, most of the previous researches, including the experimental studies and model predictions, have relied on high-frequency cyclic loadings, such as seismic loading and traffic loading $[3,8,14]$. However, no much effort has been done to investigate the deformation characteristics of soft marine soil tested under cyclic loading with low frequency, such as the tide, repeated changes in storage structure levels, and even periodic draining and recharging of the groundwater [31,32].

Thus, in this work, triaxial shear tests were conducted under cyclic loading with different low frequencies on soft marine soil. The evolutions of the axial strain and pore pressure were identified while considering the influences of the soil structure, confining stress, stress ratio, cyclic period, and waveform. Besides, an empirical model for predicting the evolution of pore pressure (ratio) is proposed. This research contributes to providing information to the settlement analysis of foundation soils in the nearshore and offshore areas under cyclic loadings with low frequency.

\section{Experimental Investigation}

2.1. Material. The representative soil tested in this work is a type of soft marine soil in Guangzhou, China. The soil samples were extracted from about $15 \mathrm{~m}$ deep marine strata, and the basic physical and mechanical properties of the soil are listed in Table 1. The soil is classified as Elastic Silt (MH) based on Unified Soil Classification System [33].

2.2. Specimen Preparation. According to Standard for Geotechnical Testing Method GB/T 50123-2019 [34], the specimens in this work were $39.1 \mathrm{~mm}$ in diameter and
TABLE 1: Basic physical and mechanical properties of the soil.

\begin{tabular}{lc}
\hline Property & Value \\
\hline Sand $(\%)$ & 4.6 \\
Silt $(\%)$ & 89.2 \\
Clay $(\%)$ & 6.2 \\
Liquid limit, $\omega_{\mathrm{L}}(\%)$ & 81 \\
Plasticity index, $I_{\mathrm{p}}$ & 43 \\
Specific gravity, $G_{\mathrm{s}}$ & 2.65 \\
Water content, $\omega(\%)$ & $87-90$ \\
Average density, $\rho\left(\mathrm{g} / \mathrm{cm}^{3}\right)$ & 1.56 \\
Structural yield stress, $q_{\text {sy }}(\mathrm{kPa})$ & $38-45$ \\
\hline
\end{tabular}

$80.0 \mathrm{~mm}$ in height, and this dimension was also adopted by previous researches [35-37].

For the undisturbed specimens, the soil blocks were obtained by the polished thin-walled sharp-edged stainless steel core cutters (with a diameter of $150 \mathrm{~mm}$ and a length of $250 \mathrm{~mm}$ ) and then transported to the laboratory. Before the cyclic loading tests, the specimens for triaxial tests were trimmed from the cores of the soil blocks by knife and wire saw [38]. For the reconstructed specimens, the soil was obtained by damaging the structure of undisturbed soil, without changing of water content and density. Similar sampling methods have been used and described by Moses et al. [14] and Liu et al. [39].

2.3. Test Procedures. A computer-controlled triaxial testing system by GDS Instruments Ltd. was adopted in this work (Figure 1). In this apparatus, the vertical stress (or displacement) is applied by a servo loading system range from 0 to $10 \mathrm{kN}$ (or $\pm 25 \mathrm{~mm}$ ), within a range of frequency between 0 and $5 \mathrm{~Hz}$. The confining pressure is applied through a GDS pressure/volume controller with a maximum value of $1 \mathrm{MPa}$. The amplitudes of the cyclic deviatoric stress and confining pressure can be controlled independently, and the phase differences between them can also be controlled independently of the amplitudes. Thus, various stress paths can be applied on the specimens using this apparatus.

In the present work, three different loading waves (i.e., trapezoidal, triangular, and rectangular waves, Figure 2) were applied in the vertical direction while the cell pressure was kept constant. Meanwhile, different confining stresses $\left(\sigma_{3}\right)$, stress ratios $\left(\eta=q_{\max } / \sigma_{3}\right)$, and cyclic periods $(T)$ were imposed. The details of the testing conditions are summarised in Table 2.

For each test, first of all, the soil specimen was placed into the pressure chamber, and subsequently, a saturated back pressure was applied until a minimum $B$-value of 0.95 was achieved [34, 40-42]. Then, the specimen was isotropically consolidated with the particular confining pressure, and the consolidation was assumed to be completed when the rate of water discharge was less than $0.1 \mathrm{~cm}^{3} / \mathrm{h}[43]$. Finally, one-way stress-controlled cyclic triaxial test was performed under undrained condition.

All the triaxial tests were conducted at an ambient temperature of $20 \pm 0.5^{\circ} \mathrm{C}$ [34]. 


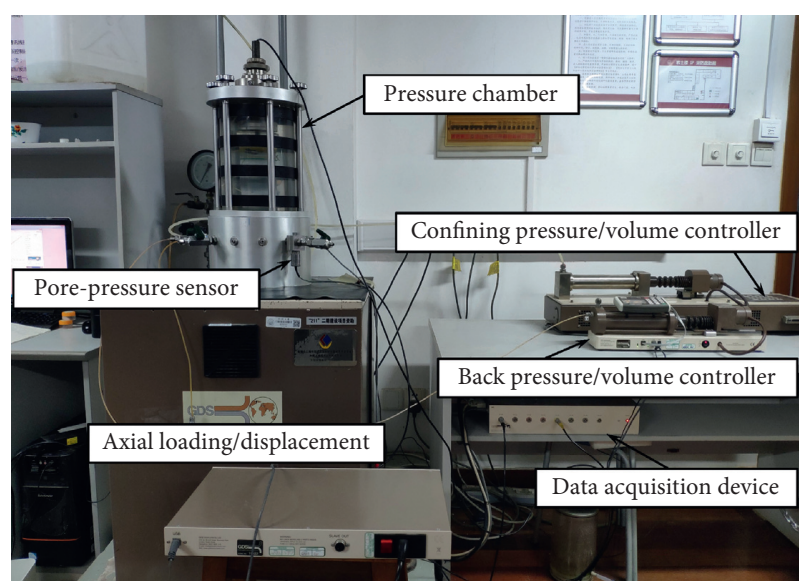

FIgURE 1: GDS triaxial testing system.
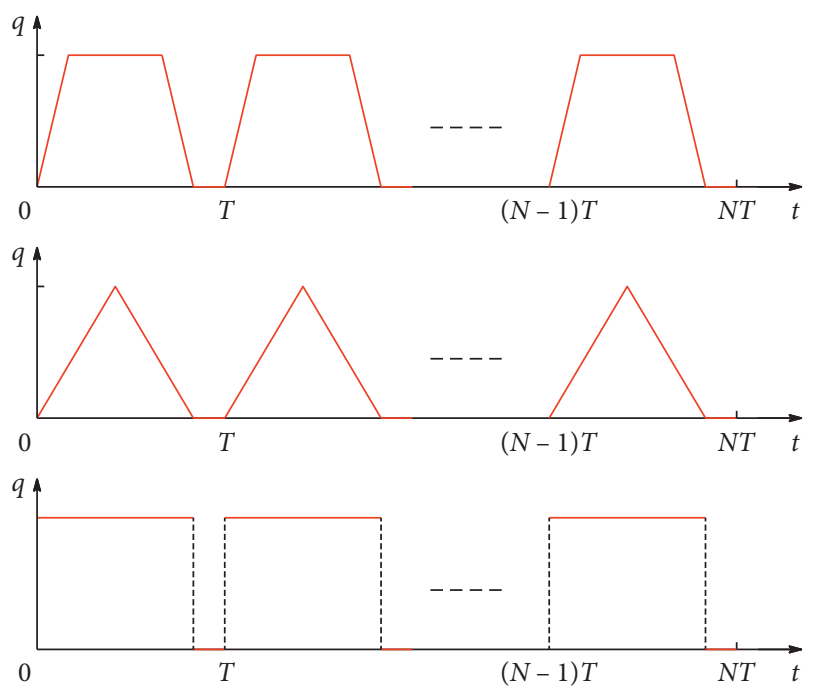

FIGURE 2: Schematic diagram of the loading waveform in this work. (a) Trapezoidal wave. (b) Triangular wave. (c) Rectangular wave.

\section{Results and Analysis}

3.1. Evolution of Deformation and Pore Pressure. Typical evolutions of deformation (represented by axial strain $\varepsilon_{\mathrm{a}}$ ) and pore pressure $\mu$ with cyclic number $N$ for the specimen under the confining stress of $100 \mathrm{kPa}$ (trapezoidal wave, $\eta=0.6$, and $T=60 \mathrm{~min}$ ) are plotted in Figure 3. Note that only the maximum values in each cycle are presented. The curves in the figure demonstrate that the axial strain and pore pressure increase sharply at the beginning of shearing, which is different from the previous research under highfrequency cyclic loading $[6,41]$. The main reason could be that soft marine soil in this work primarily comprises plateshaped particles with "face-face," "face-edge," and "edgeedge" contacts, presenting a flocculated structure as an overall structure (Figure 4). Consequently, the dissipation of pore water pressure is limited due to the small size of the pore structure and the poor connectivity between them, especially in the case under high-frequency cyclic loading (i.e., $1 \mathrm{~Hz}$ ). Nevertheless, for the cyclic loading with low
TABle 2: Summary of the testing conditions.

\begin{tabular}{|c|c|c|c|c|}
\hline State & Waveform & $\sigma_{3}(\mathrm{kPa})$ & $\eta(-)$ & $T(\min )$ \\
\hline \multirow{21}{*}{ Undisturbed } & \multirow{9}{*}{ Trapezoidal } & 20 & 0.6 & 60 \\
\hline & & 40 & 0.6 & 60 \\
\hline & & 100 & 0.2 & 60 \\
\hline & & 100 & 0.4 & 60 \\
\hline & & 100 & 0.6 & 60 \\
\hline & & 100 & 0.8 & 60 \\
\hline & & 200 & 0.6 & 20 \\
\hline & & 200 & 0.6 & 40 \\
\hline & & 200 & 0.6 & 60 \\
\hline & \multirow{7}{*}{ Triangular } & 20 & 0.67 & 60 \\
\hline & & 40 & 0.6 & 60 \\
\hline & & 100 & 0.6 & 60 \\
\hline & & 150 & 0.67 & 60 \\
\hline & & 200 & 0.6 & 20 \\
\hline & & 200 & 0.6 & 40 \\
\hline & & 200 & 0.6 & 60 \\
\hline & \multirow{5}{*}{ Rectangular } & 40 & 0.6 & 60 \\
\hline & & 100 & 0.6 & 60 \\
\hline & & 200 & 0.6 & 20 \\
\hline & & 200 & 0.6 & 40 \\
\hline & & 200 & 0.6 & 60 \\
\hline \multirow{2}{*}{ Reconstructed } & \multirow{2}{*}{ Triangular } & 20 & 0.67 & 60 \\
\hline & & 150 & 0.67 & 60 \\
\hline
\end{tabular}

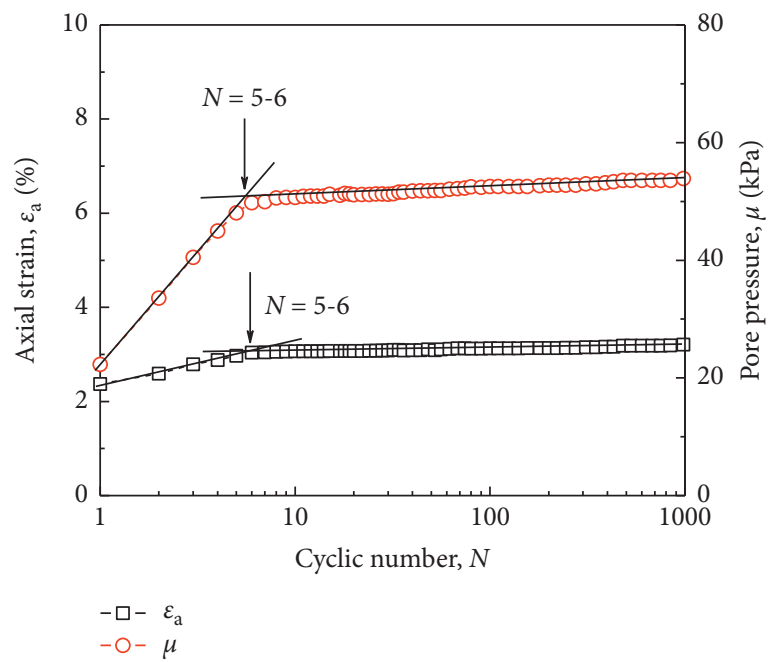

FIGURE 3: Evolutions of axial strain and pore pressure with cyclic number.

frequency in this work, much more time is available for pore water pressure dissipation. Some pores expanded and became connected under hydraulic gradient action because part of the free water in the soil discharged outwards through the connected macropores. Moreover, the pore space (interaggregate pores) of the soil is reduced, and the aggregates have a tighter contact through a series of adjustments that consist of both elastic and plastic deformation [44].

In addition, the results in Figure 3 also reveal that, after several time cycles, the changes in the axial strain and pore pressure become stable or slowly increase. The threshold is 


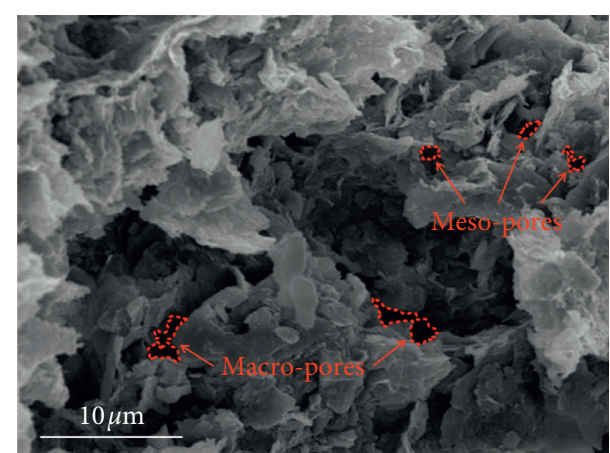

FIGURE 4: SEM picture of the undisturbed specimen before consolidation.

around five to six cycles, and the values corresponding to $N=6$ are both over $95 \%$ of the final values. Therefore, for clarity, only six cycles were present in the following analysis.

3.2. Influence of Confining Stress. The stress-strain curves of undisturbed specimens under four different confining stresses of 20, 40, 100, and $200 \mathrm{kPa}$ are plotted in Figure 5(a). The evolutions of the pore pressure ratios $\left(\mu / \sigma_{0}^{\prime}\right.$, where $\sigma_{0}^{\prime}$ is the initial effective stress) with dimensionless time $(t / T)$ are presented in Figure 5(b). Generally, plastic deformation (Figure 5(a)) and the pore pressure ratio (Figure 5(b)) accumulate with decreased increments under cyclic loading, and these phenomena agree with the previous research on saturated soil under higher frequency cyclic loading [41, 45].

Furthermore, the curves in Figure 5(a) reveal that the cumulative strain generally increases with increasing confining stress. Meanwhile, the pore pressure ratio under higher confining stress is a bit higher than that under a lower confining stress, except for the case under the confining stress of $20 \mathrm{kPa}$ (Figure 5(b)). These observations are consistent with that reported in the literature $[35,46]$.

The deformation and pore pressure characteristics in the macroscope are intrinsically determined by the microstructure and stress state of the specimen. For the specimen tested under the confining stress of $20 \mathrm{kPa}$ whose effective stress is lower than the structural yield stress (overconsolidation stage), the soil is primarily under a stage of self-adjustment in structure with elastic deformation for a long time. Thus, the pore pressure presents a significant hysteresis loop during the processes of loading and unloading. Meanwhile, for the specimen tested under the confining stress of $40 \mathrm{kPa}$ or $100 \mathrm{kPa}$ whose effective stress is around or slightly greater than the structural yield stress, the residual structural strength might still work to a certain extent. However, the valid part (shadowed part in Figure 6) of the effective stress, which is above the value of initial effective stress (equal to confining stress), also increases significantly. Hence, more plastic deformation occurs instead of elastic deformation, leading to a significant increase in strain.

In addition, due to the decrease in void ratio, the permeability coefficient decreases correspondingly [44], resulting in notable decreases and increases in the peak and residual values of the pore pressure ratio in each cycle, respectively. Furthermore, for the specimen under the confining stress of $200 \mathrm{kPa}$ whose effective stress is well over the structural yield stress, the structure of soil has almost been damaged and further plastic deformation occurs. Then, under the sustained cyclic loading, the soil structure softens, and an increased deformation and higher pore pressure are observed.

Moreover, a significant increase in the pore pressure ratio is observed during the holding stage, which is predominantly because the measured pore pressure could be a bit delayed because the sensor was installed on the bottom of the specimen. This phenomenon gradually fades as the pore pressure redistributes during the cyclic period. Then, the measured value is much closer to the real value, accompanied by the homogenisation and accumulation of the pore pressure in the specimen [7].

3.3. Influence of Stress Ratio. The stress-strain curves and the evolution of the pore pressure for the undisturbed specimens with different cyclic stress ratios are illustrated in Figure 7. Only the values corresponding to the maximum and minimum strains in each cycle for the specimen with a low-stress ratio (0.2 and 0.4 ) are presented in Figure 7 (a) for clarity. The curves in the figure demonstrate that the stress-strain relationship is sensitive to the cyclic stress ratio, as the specimen that experienced a higher cyclic stress ratio presents a higher plastic deformation and generally accumulates a higher pore pressure. This conclusion agrees with those reported by Tang et al. [7] and Guo et al. [38].

For the case with a lower stress ratio, the specimen is under the initial shear stage where the strain is relatively small, and the migrated water due to the deviatoric stress is primarily free water. With the increase in the stress ratio, the effective stress increases significantly, causing a decrease in the macro-/mesopores (Figure 4), resulting in a notable deformation of the specimen in the macroscope. Meanwhile, more particles change to "face-face" associations, and the pores are primarily occupied by bound water, which exhibits a stronger viscosity than free water [6]. If the increased hydraulic gradient from the further increased deviatoric stress is high enough to overcome the viscosity and shear resistance of the loosely bound water, the loosely bound water in the diffused layer could transform to free water, leading to a further increase in deformation $[44,47,48]$.

3.4. Influence of Cyclic Period. The stress-strain curves and the evolution of the pore pressure for the undisturbed specimens under three different cyclic periods $(T=1 / f)$ are depicted in Figure 8. The results demonstrate that the strain under a lower-frequency (higher cyclic period) shearing is much higher than a higher frequency shearing, and this phenomenon is consistent with the previous research with high-frequency dynamic loading [24, 49, 50]. The primary reason is that the specimen under a lower frequency experiences a longer period of action of effective stress, and the pore pressure can adjust more sufficiently. Moreover, cyclic 


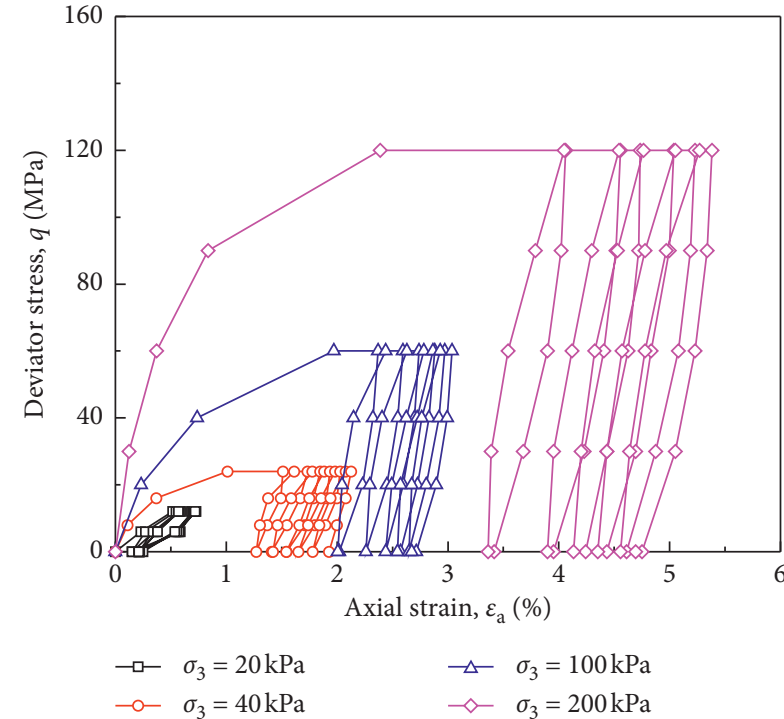

(a)

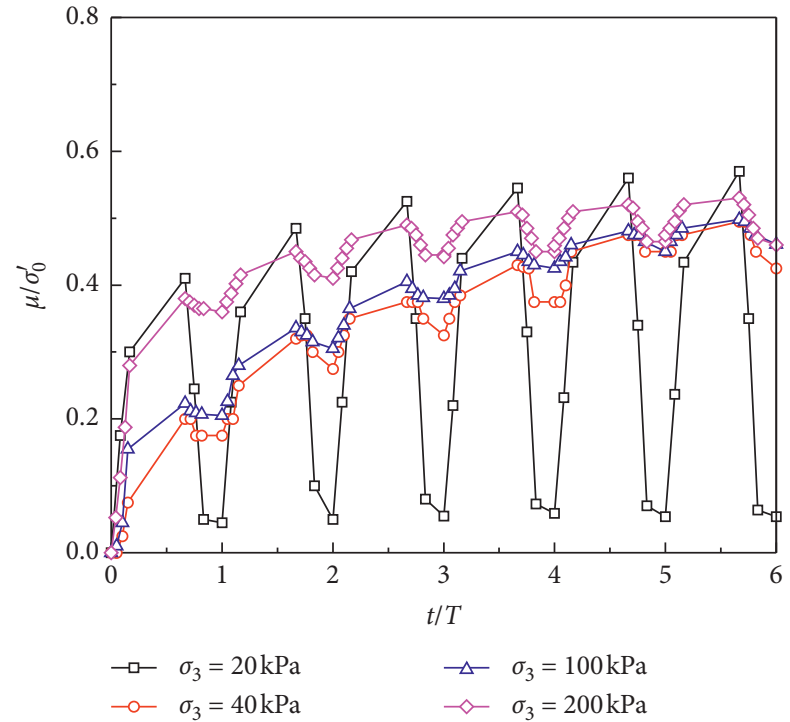

(b)

FIGURE 5: Stress-strain curve and evolution of the pore pressure ratio under different confining stresses (trapezoidal wave, $\eta=0.6$, and $T=60 \mathrm{~min}$ ). (a) Stress-strain curve. (b) Evolution of the pore pressure ratio.

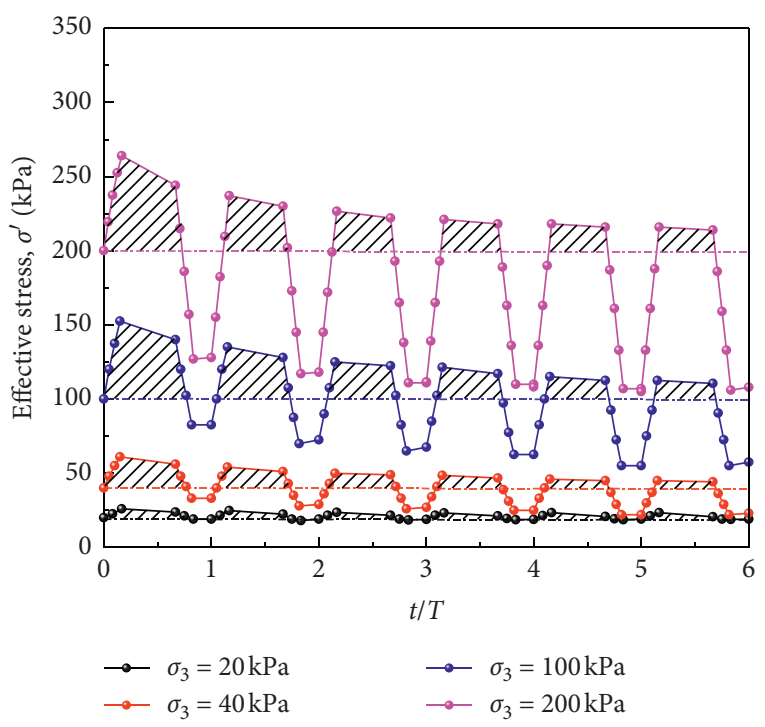

FIGURE 6: Evolutions of the effective stresses with dimensionless time under different confining stresses (trapezoidal wave, $\eta=0.6$, and $T=60 \mathrm{~min}$ ).

creep might also occur during the long-term cyclic loading process $[51,52]$.

3.5. Influence of Loading Waveform. The stress-strain curves and evolution of the pore pressure for the undisturbed specimens under different waveforms are displayed in Figure 9. The specimen tested under the rectangular wave presents the largest axial strain, followed by the specimen under the trapezoidal wave and then the triangular wave. The rectangular wave is applied to the specimen in one step and then stays for a long period (e.g., $50 \mathrm{~min}$ for $T=60 \mathrm{~min}$ ) instead of gradually increasing from zero to the target value. Consequently, the evolution of the pore pressure under the rectangular wave is much quicker, especially at the beginning of loading (Figure 9(b)). Compared with the trapezoidal and triangular waves, the averaged value of the valid parts (shadowed parts in Figure 10) of the effective stress of rectangular wave is much higher than the other two, contributing to the deformation of the specimen. Similarly, for the trapezoidal wave, a steady period occurs between the loading and unloading stages; thus, the averaged value of the valid parts of the effective stress in a cycle is much higher than that of the triangular wave.

In addition, the evolution of the maximum axial strains in six cycles for the specimens tested under different waveforms with different confining stresses and cyclic periods is summarised in Figure 11. With the increase in the load level (confining stress) and cyclic period, the difference in maximum strain between the three waveforms gradually becomes less obvious. The interpretation could be from the point of the relationship of the averaged effective stress with the structural yield stress [53]. If the averaged effective stress is around or just a bit higher than the yield stress, different waveforms present various effects on the strains. This is because the axial stress upon loading and unloading for the trapezoidal and triangular waves is sometimes much lower than the structural yield stress, which is different from the case for the rectangular wave. Nevertheless, with the increase in deviatoric stress, the change rate of loading and unloading for the trapezoidal and triangular wave is also increased. This results in the period in which the effective stress is higher than the structural yield stress which is significantly increased. As a result, the influence of waveforms is not as obvious as before.

Moreover, for the specimen tested under a short cyclic period, the dissipation of pore water pressure is limited, and 


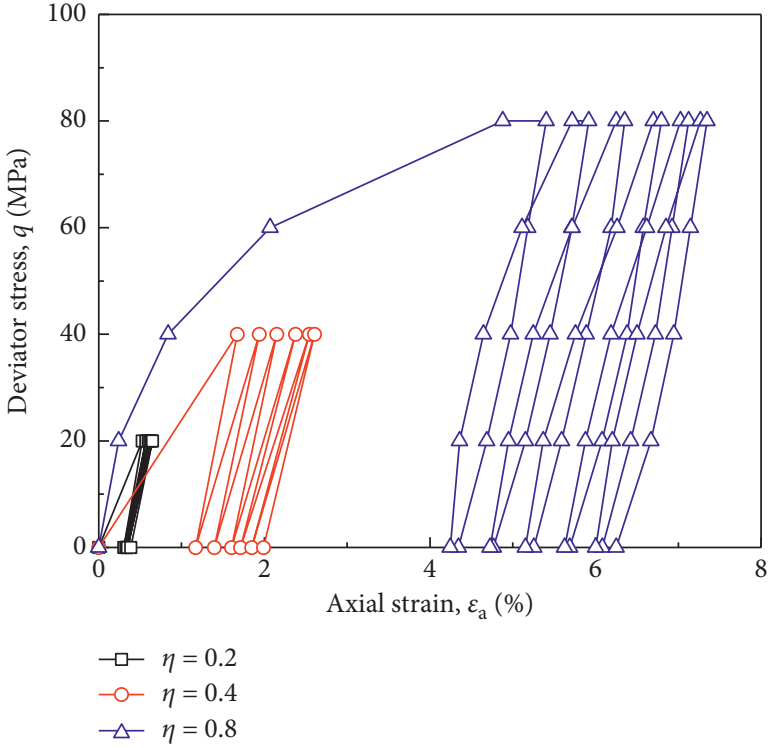

(a)

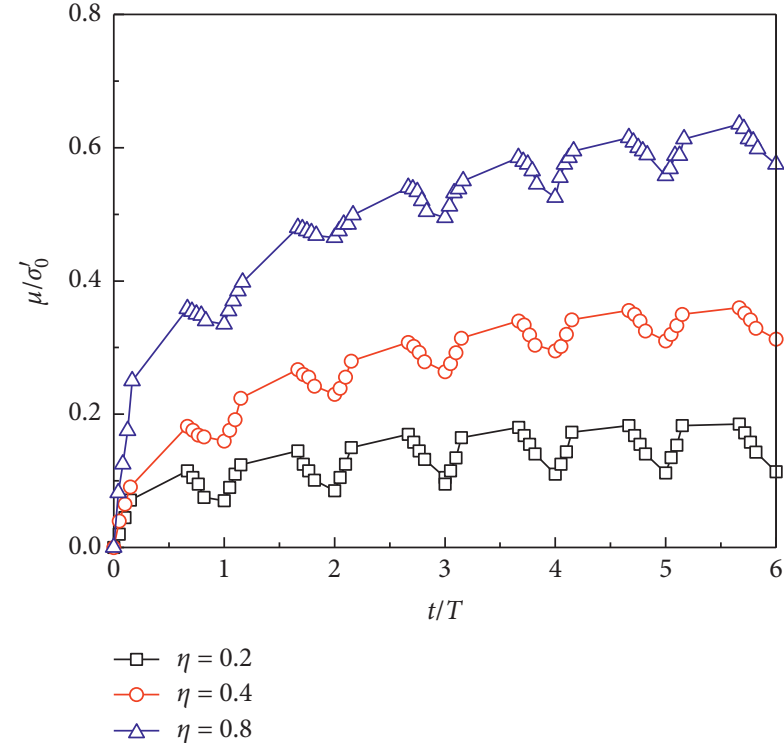

(b)

FiguRE 7: Stress-strain curve and evolution of the pore pressure ratio under different stress ratios (trapezoidal wave, $\sigma_{3}=100 \mathrm{kPa}$, and $T=60 \mathrm{~min}$ ). (a) Stress-strain curve. (b) Evolution of the pore pressure ratio.

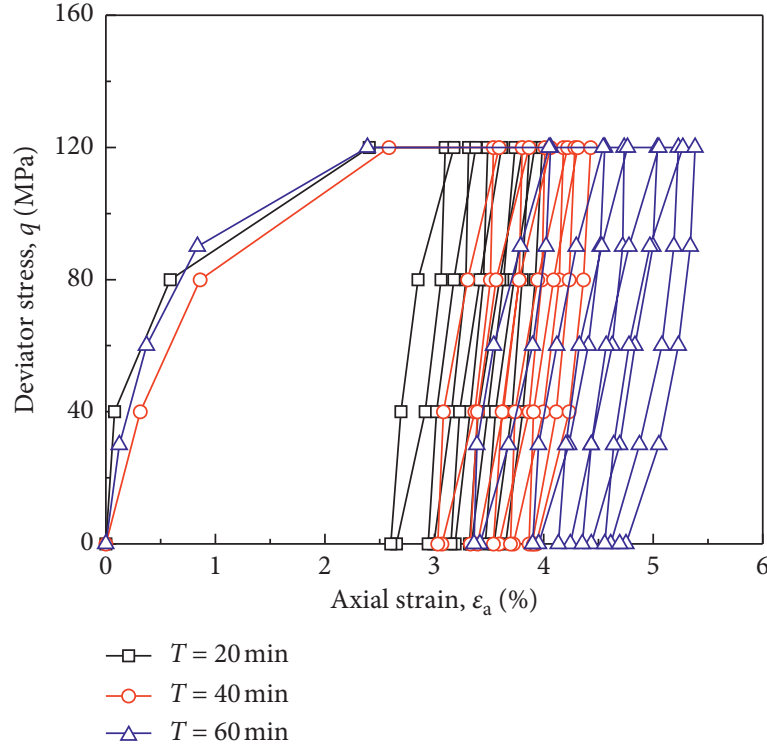

(a)

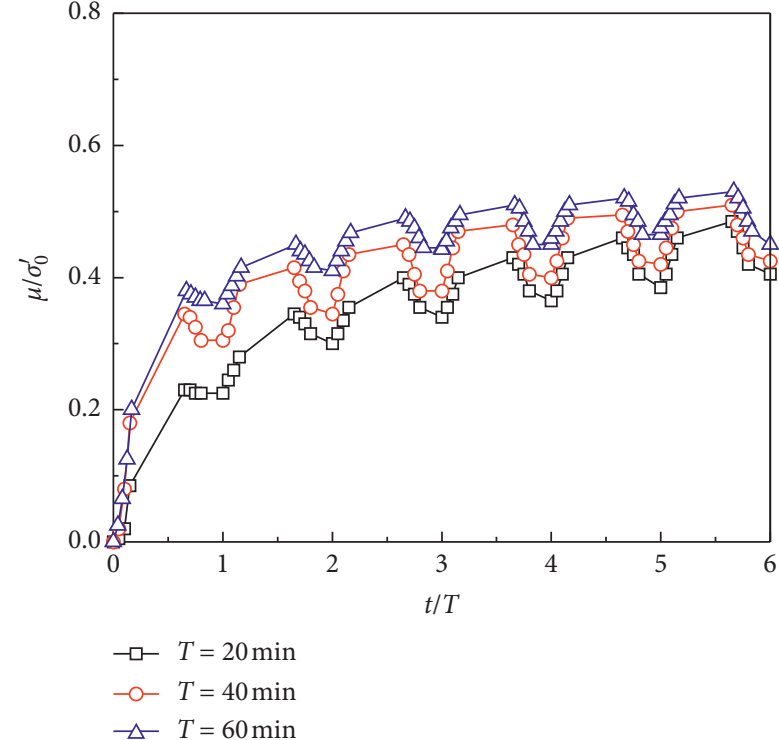

(b)

FIGURE 8: Stress-strain curve and evolution of the pore pressure ratio under different cyclic periods (trapezoidal wave, $\sigma_{3}=100 \mathrm{kPa}$, and $\eta=0.6$ ). (a) Stress-strain curve. (b) Evolution of the pore pressure ratio.

the deformation of the soil structure may be inadequate, where the soil could maintain a certain degree of structure [38]. However, for the specimen tested under a long cyclic period, much more time is available for pore pressure adjustment and soil aggregate rearrangement. Thus, the difference in maximum strain under the different loading waveforms is decreased.
3.6. Difference between Undisturbed and Reconstructed Specimens. The representative stress-strain curves and evolution of the pore pressure ratio for undisturbed and reconstructed specimens are presented in Figures 12 and 13, respectively. The results indicate that the undisturbed specimen generally exhibits a higher strength and shear modulus (reflected by the shape and slope of the curve), 


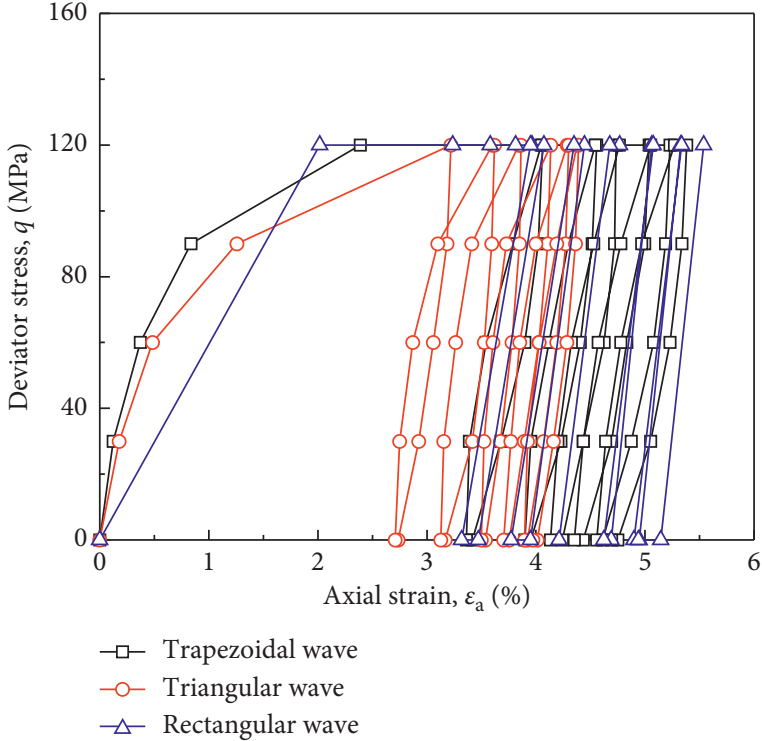

(a)

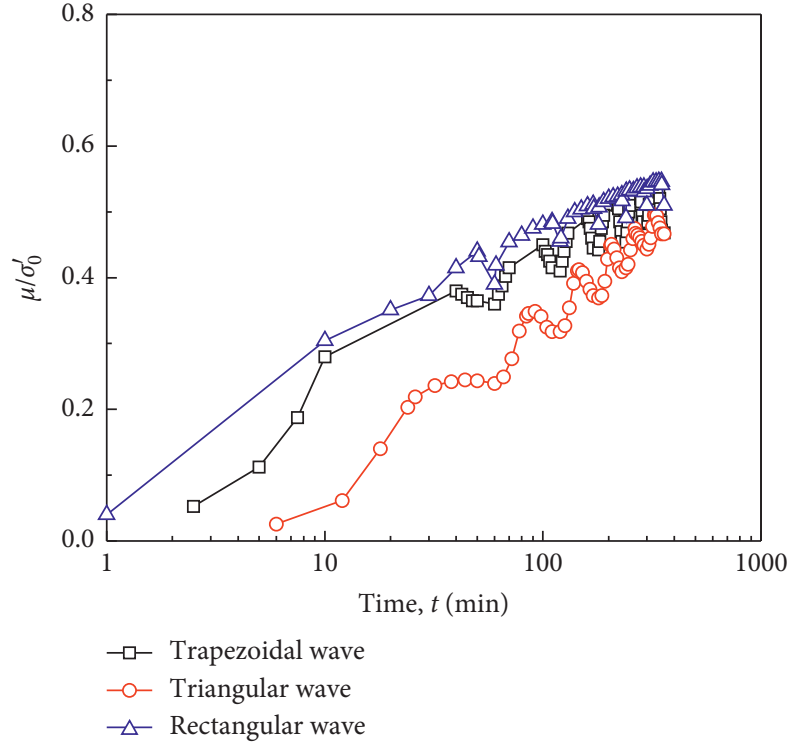

(b)

FIgURE 9: Stress-strain curve and evolution of the pore pressure ratio under different waveforms $\left(\sigma_{3}=200 \mathrm{kPa}, \eta=0.6\right.$, and $\left.T=60 \mathrm{~min}\right)$. (a) Stress-strain curve. (b) Evolution of the pore pressure ratio.

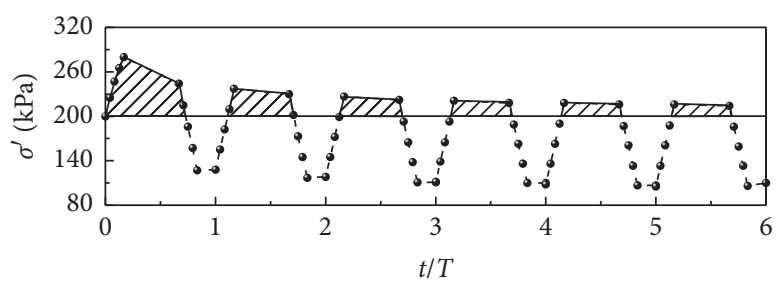

- - Trapezoidal wave

(a)

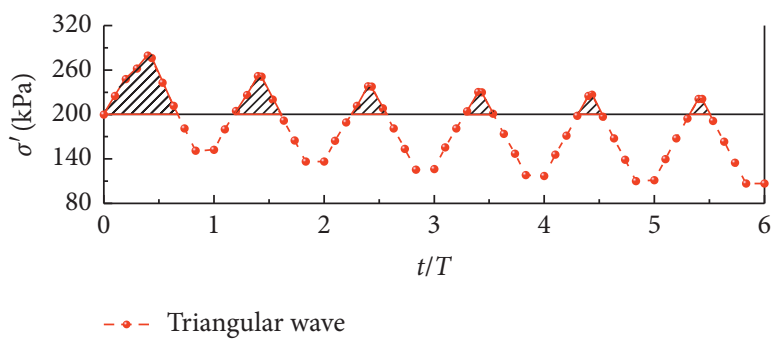

(b)

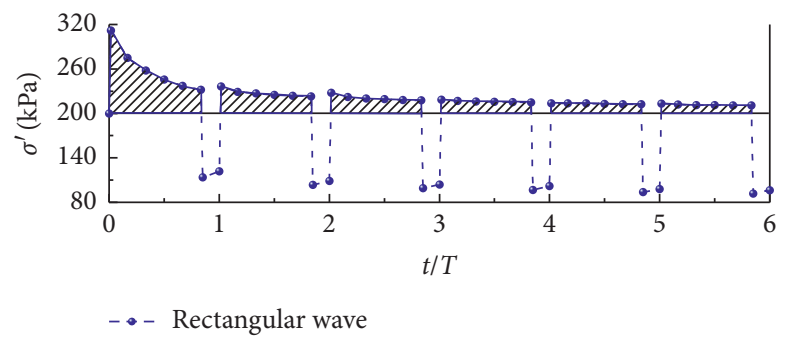

(c)

FIgURE 10: Effective stresses under different waveforms $\left(\sigma_{3}=200 \mathrm{kPa}, \eta=0.6\right.$, and $\left.T=60 \mathrm{~min}\right)$.

confirming the existence of a structural effect that also exists in most natural soils [44, 54]. Specifically, in the case in which the confining pressure is lower than the structural yield stress (Figure 12(a)), the deformation of the overconsolidated undisturbed specimen is dominated by elastic deformation, and the internal structure of the specimen could be self-adjusted to balance the external load. Significant plastic deformation is found in the reconstructed specimen, which indicates that the structure cannot balance the external load, and the deformation cannot be restored in time. In the case in which the confining pressure is much higher than the structural yield stress (Figure 13(a)), the deformation is dominated by plastic deformation. This is because the structure is damaged for both undisturbed and reconstructed specimens. That is, the bonds of soil particles are disrupted, and the effects of the soil structure gradually vanish [38]. This results in the stress-strain curve of the undisturbed specimen approaching the same value as the reconstructed specimen.

The pore pressure of the undisturbed specimen is a bit lower than the reconstructed specimen as shown in Figure 12(b). This phenomenon could be interpreted from 


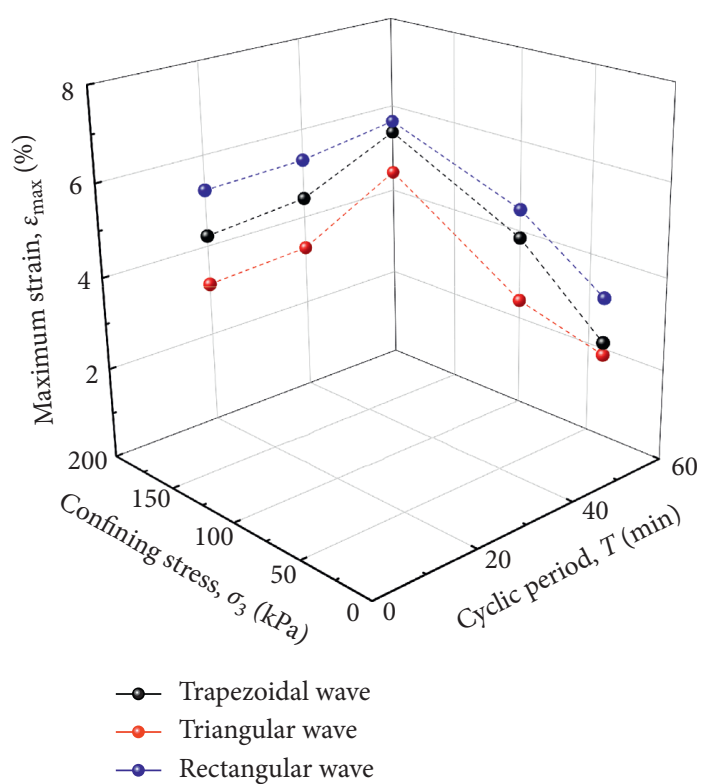

FIgURE 11: Maximum strain versus confining stress and cyclic period under different waveforms $(\eta=0.6)$.

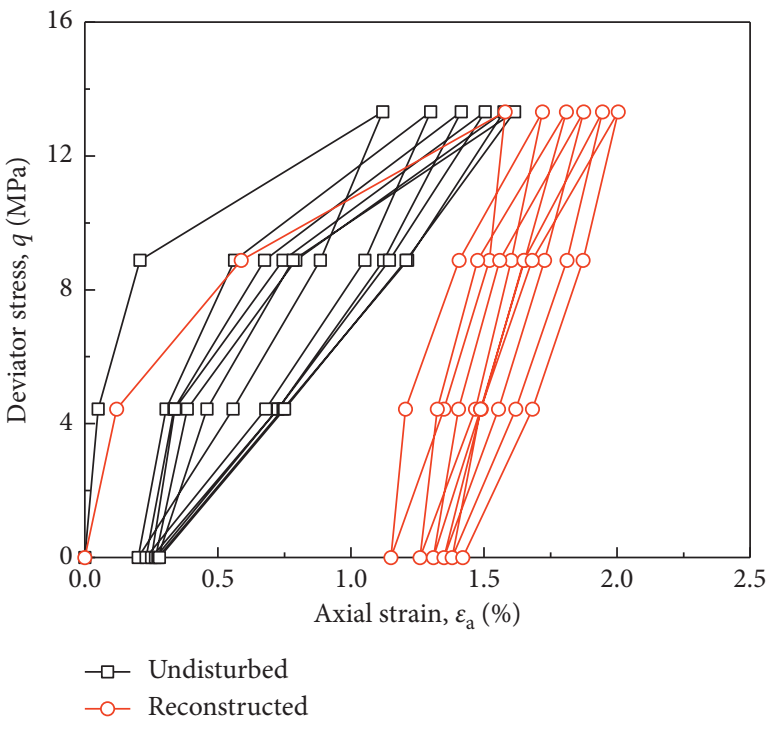

(a)

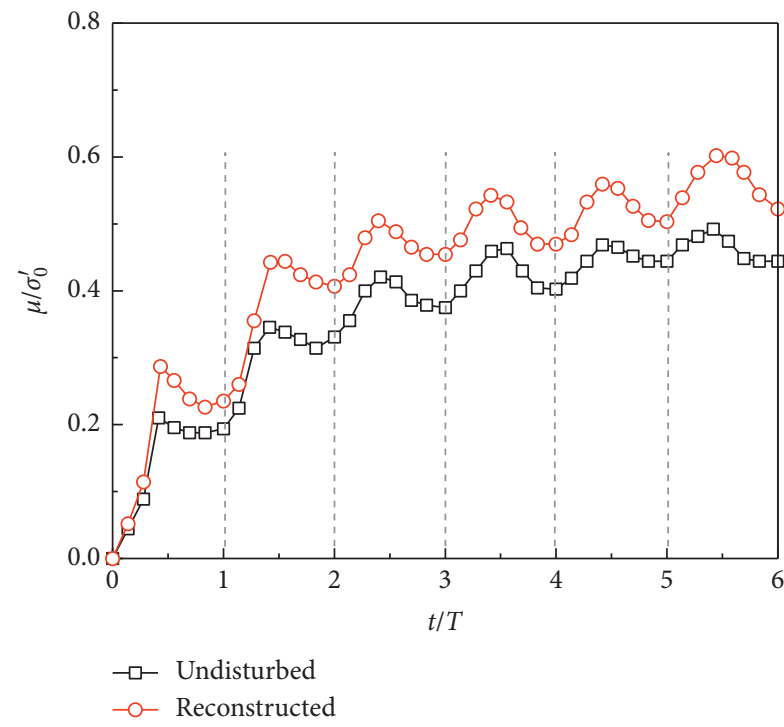

(b)

FIGURE 12: Stress-strain curve and evolution of the pore pressure ratio of the undisturbed and reconstructed specimens (triangular wave, $\sigma_{3}=20 \mathrm{kPa}, \eta=0.67$, and $T=60 \mathrm{~min}$ ). (a) Stress-strain curve. (b) Evolution of the pore pressure ratio.

the aspect of microstructures, as the flocculated structure in the undisturbed soil could contribute to restraining the seepage/adjustment of pore water [44]. Nevertheless, if the confining stress is much higher than the structural yield stress, the difference between the two specimens is no longer significant because the structural effect is almost eliminated for both specimens (Figure 13(b)).

\section{Empirical Model for the Pore Pressure}

Two types of empirical models for predicting the pore pressure (ratio) upon cyclic loading are widely used in the literature. Specifically, Hyde and Ward [22] proposed a power model for silty clay under unstrained conditions using monotonic strain-controlled cyclic triaxial tests. Afterward, a simplified power model was proposed by Huang et al. [24] for Shanghai clay as follows:

$$
\frac{\mu}{\sigma_{0}^{\prime}}=a N^{b}
$$

where $\mu$ is the pore pressure, $\sigma_{0}^{\prime}$ is the initial mean effective stress, $N$ is the cyclic number, and $a$ and $b$ are the model parameters depending on the cyclic stress. 


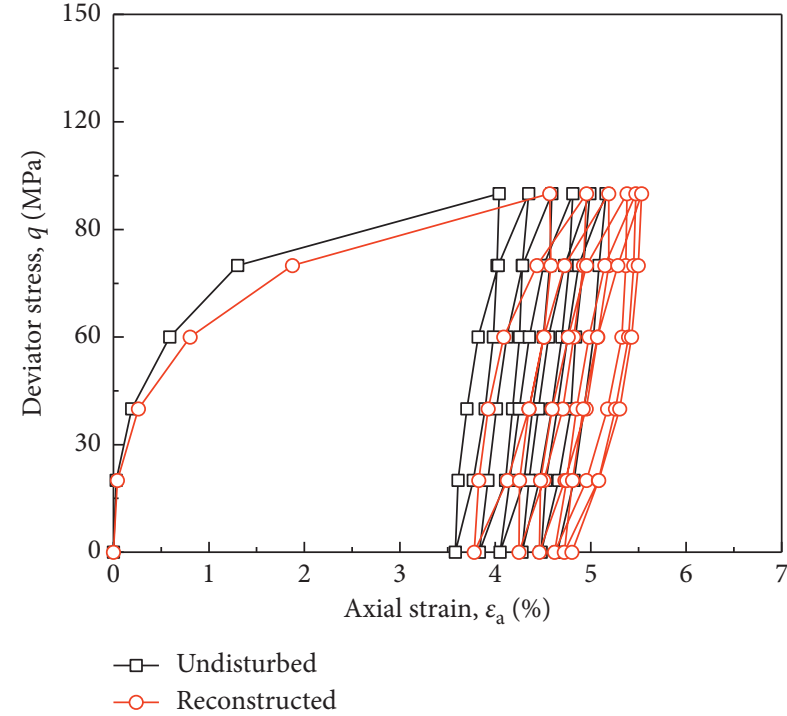

(a)

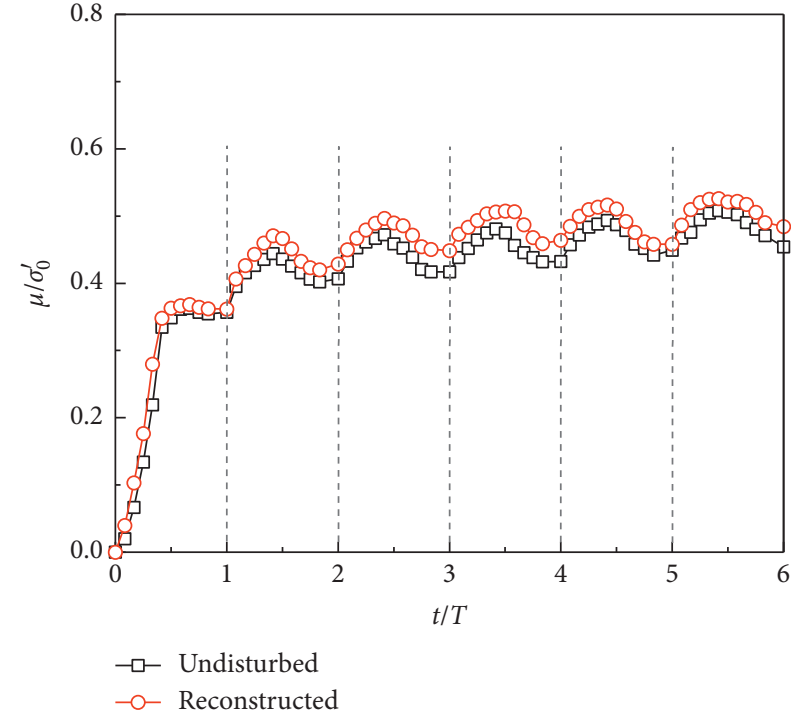

(b)

FIGURE 13: Stress-strain curve and evolution of the pore pressure ratio of the undisturbed and reconstructed specimens (triangular wave, $\sigma_{3}=150 \mathrm{kPa}, \eta=0.67$, and $T=60 \mathrm{~min}$ ). (a) Stress-strain curve. (b) Evolution of the pore pressure ratio.

Ohara and Matsuda [25] conducted a series of straincontrolled cyclic simple shear tests on kaolinite clay under undrained conditions and developed a hyperbolic model to describe the pore pressure development with respect to the cyclic numbers. On this basis, considering that it is difficult to determine the model parameters by cyclic strain, a similar hyperbolic model was suggested by Paul et al. [26], as follows:

$$
\frac{\mu}{\sigma_{\mathrm{vc}}^{\prime}}=\frac{N}{A+B N},
$$

where $\sigma_{\mathrm{vc}}^{\prime}$ is the effective confining pressure, which is equal to $\sigma_{0}^{\prime}$ in equation (1) for isotropic consolidation. In addition, $A$ and $B$ are model parameters, which can be expressed as a function of the stress state (confining stress), loading parameter (i.e., stress ratio and loading frequency), and soil property (e.g., plasticity index). Thus, Ren et al. [27] modified equation (2) into the following:

$$
\frac{\mu}{p_{0}}=\frac{N^{B}}{A+C N^{B}}
$$

where $p_{0}$ is the initial mean effective stress, which is equal to $\sigma_{\mathrm{vc}}^{\prime}$ in equation (2) for isotropic consolidation. Furthermore, $A, B$, and $C$ are model parameters that depend on the stress state and physical properties of the soil, and setting $B$ equal to 0.5 is recommended by the authors.

Using the aforementioned empirical equations (equations (1)-(3)) to simulate the pore pressure (ratio) in this work (Figure 14), the results reveal that equations (2) and (3) could fit the tested results but are not accurate enough for the cycles at initial shearing. In contrast, equation (1) seems unsuitable for predicting such low-frequency conditions. The reason could be that the above models were proposed on the basis of experiments conducted under the loading

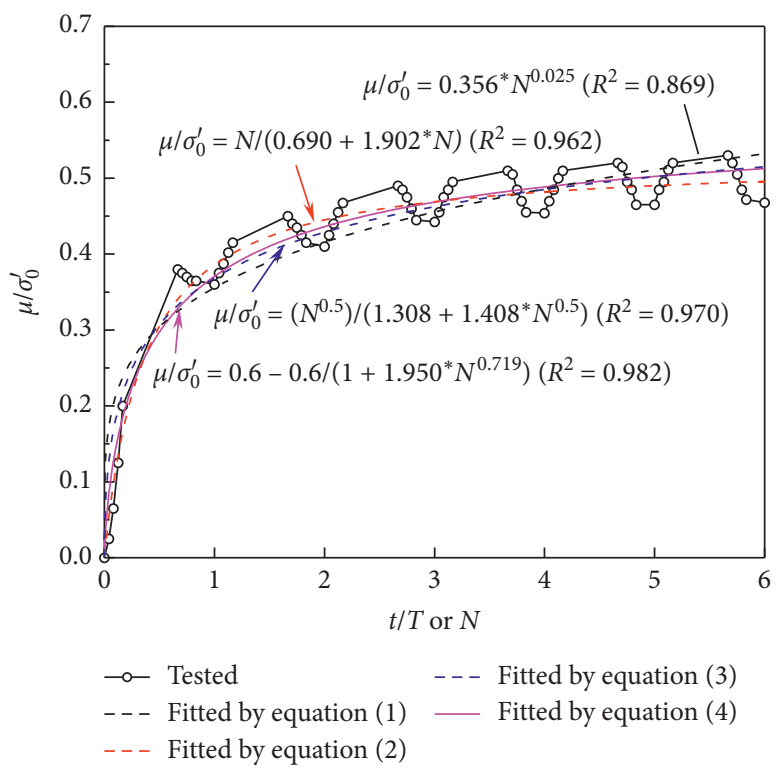

FIGURE 14: Comparison of the pore pressure ratio computed by the proposed model (equation (4)), the power model (equation (1)), and the hyperbolic models (equations (2) and (3)) with experimental data (equations (1)-(3) was proposed by Huang et al. [24], Paul et al. [26], and Ren et al. [27], resp.).

condition with high cyclic stress with high frequency, where the pore pressure would accumulate and increase steeply, even resulting in a failure of soil within a few cycles. Under lower cyclic stress level with low frequency, however, the pore pressure would accumulate at a smaller rate, and the increment of pore pressure will decrease over loading cycles. When the increment of pore pressure is small enough and equal to its dissipation over a long time, the generated pore pressure will finally tend to be plateaued without leading to a 

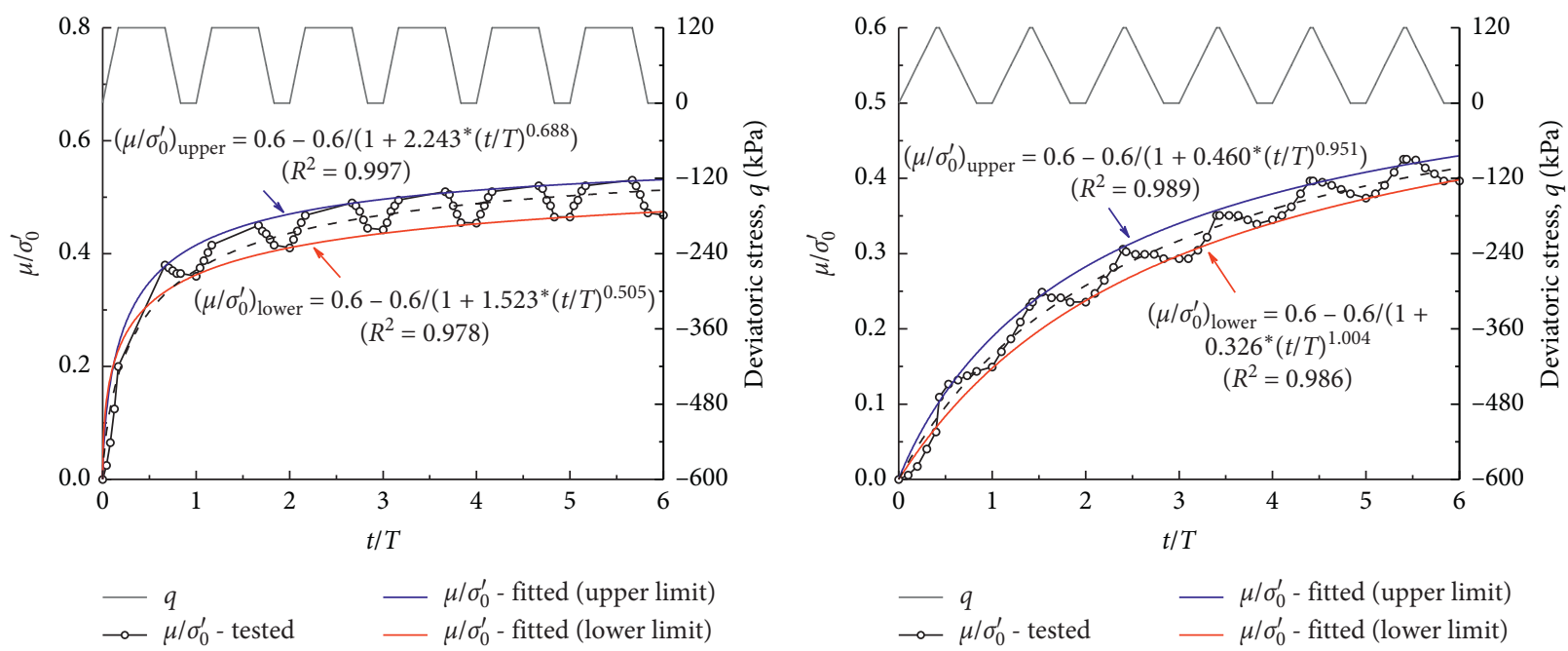

(a)

(b)
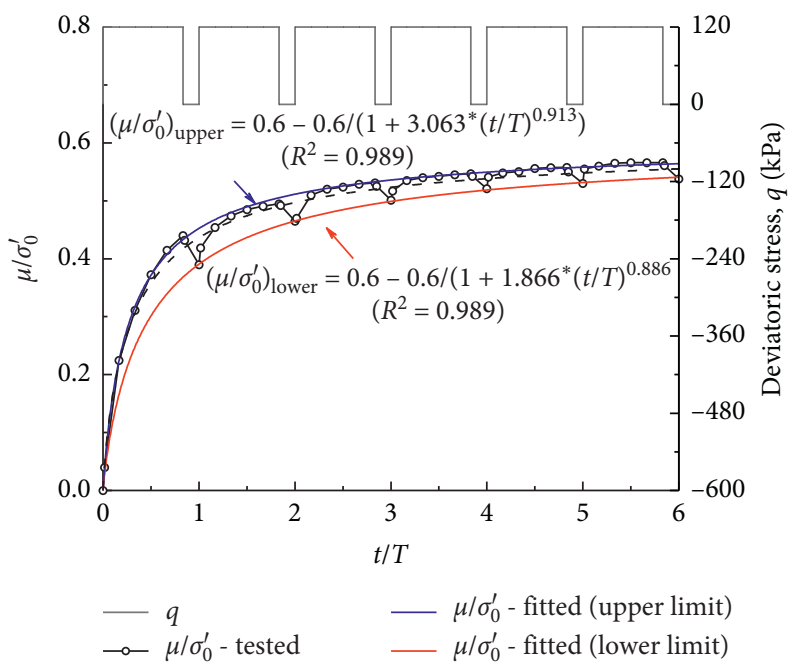

(c)

FIGURE 15: Evolutions of the pore pressure ratio/deviatoric stress with dimensionless time $\left(\sigma_{3}=200 \mathrm{kPa}, \eta=0.6\right.$, and $\left.T=60 \mathrm{~min}\right)$. (a) Under trapezoidal wave. (b) Under triangular wave. (c) Under rectangular wave.

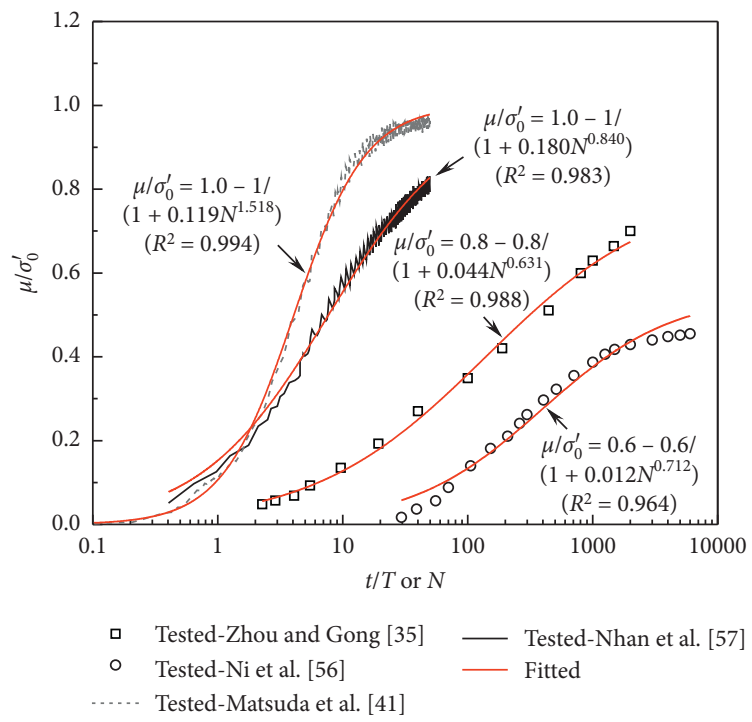

FIGURE 16: Comparison between the proposed model simulations and experimental results in the literature. 
failure of soil. This has been experimentally confirmed by many researchers (e.g., Zhou and Gong [35], Moses and Rao [55], Cui et al. [36], and Ren et al. [27]).

Therefore, to accurately predict the undrained pore pressure under low-frequency cyclic loading conditions, a new model is proposed as follows:

$$
\frac{\mu}{\sigma_{0}^{\prime}}=\eta-\frac{\eta}{1+a(t / T)^{m}}
$$

where $\mu$ is the pore pressure, $\sigma_{0}^{\prime}$ is the initial effective stress, $t /$ $T$ is the dimensionless time, $\eta$ is the stress ratio, and $a$ and $m$ are model parameters corresponding to the confining stress, frequency, waveform, and soil properties, respectively.

The fitting resulting from equation (4) was also included in Figure 14 for comparison. Moreover, the tested and fitting results of the pore pressure ratio with dimensionless time under three different loading waveforms (deviatoric stress is also included) are illustrated in Figure 15. The results demonstrate that the proposed model equation (4) in this work could accurately fit the evolution of the pore pressure ratios in terms of both the mean value (mesh line) and the upper and lower limits (blue and red solid lines).

Furthermore, to further verify the proposed model, the fitting results and the measured results in the literature (Zhou and Gong [35], Ni et al. [56], Matsuda et al. [41], and Nhan et al. [57]) of the pore pressure ratio for soft soil under higher frequency (i.e., $0.1-1 \mathrm{~Hz}$ ) are displayed in Figure 16. The results reveal that the proposed model could fit the testing results effectively.

\section{Conclusions}

Using the triaxial test system, the deformation characteristics of soft marine soil under cyclic loading with low frequency were determined, considering the influences of the confining stress, stress ratio, cyclic period, waveform, and structural effect. The results allow the following conclusions to be drawn:

(1) The specimens tested under low confining stresses (overconsolidated state) mainly reveal elastic deformation and hysteretic phenomenon of pore pressure, while the specimens tested under high confining stresses (normal consolidated state) generally accumulate plastic deformation and pore pressure, and the increments decrease with the cyclic number significantly.

(2) Specimen tested under higher stress ratio with longer cyclic period generally presents higher deformation and pore pressure, due to the fact that the specimen had experienced an effective stress with higher level and longer period, especially for the case that the effective stress was higher than the structural yield stress.

(3) The rectangular wave contributes most to the axial deformation, cumulated strain, and pore pressure, followed by the trapezoidal wave and then the triangular wave. However, with the increase in the load level and cyclic period, the influence of the waveform declined gradually.

(4) The undisturbed specimen generally exhibits higher resistance to deformation with a lower measured pore pressure than the reconstructed specimen. Nevertheless, the difference is not significant if the confining stress is much greater than the structural yield stress.

(5) On the basis of experimental tests, a new empirical model for predicting pore pressure is proposed. The fitting results present a satisfactory agreement between the measured and predicted values.

\section{Data Availability}

The data used to support the findings of this study are available from the corresponding author upon request.

\section{Conflicts of Interest}

The authors declare that they have no conflicts of interest.

\section{Acknowledgments}

The support of National Natural Science Foundation of China (nos. 51908288 and 42002266) is greatly appreciated.

\section{References}

[1] K. H. Andersen, "Bearing capacity under cyclic loading-offshore, along the coast, and on land. The 21st Bjerrum lecture presented in Oslo, 23 november 2007," Canadian Geotechnical Journal, vol. 46, no. 5, pp. 513-535, 2009.

[2] L. Hu and J. Ding, "Mechanical behavior of marine clay under wave loading," International Journal of Offshore and Polar Engineering, vol. 20, no. 1, pp. 72-79, 2010.

[3] X.-W. Ren, Y.-Q. Tang, J. Li, and Q. Yang, "A prediction method using grey model for cumulative plastic deformation under cyclic loads," Natural Hazards, vol. 64, no. 1, pp. 441-457, 2012.

[4] Q. Yang, Y. Ren, J. Niu, K. Cheng, Y. Hu, and Y. Wang, "Characteristics of soft marine clay under cyclic loading: a review," Bulletin of Engineering Geology and the Environment, vol. 77, no. 3, pp. 1027-1046, 2018.

[5] G. G. Moses and S. N. Rao, "Degradation in cemented marine clay subjected to cyclic compressive loading," Marine Georesources \& Geotechnology, vol. 21, no. 1, pp. 37-62, 2003.

[6] L.-L. Li, H.-B. Dan, and L.-Z. Wang, "Undrained behavior of natural marine clay under cyclic loading," Ocean Engineering, vol. 38, no. 16, pp. 1792-1805, 2011.

[7] Y.-Q. Tang, J. Zhou, S. Liu, P. Yang, and J.-X. Wang, "Test on cyclic creep behavior of mucky clay in shanghai under step cyclic loading," Environmental Earth Sciences, vol. 63, no. 2, pp. 321-327, 2011.

[8] T. Wichtmann, K. H. Andersen, M. A. Sjursen, and T. Berre, "Cyclic tests on high-quality undisturbed block samples of soft marine Norwegian clay," Canadian Geotechnical Journal, vol. 50, no. 4, pp. 400-412, 2013.

[9] H. Y. Lei, B. Li, H. B. Lu, and Q. Ren, "Dynamic deformation behavior and cyclic degradation of ultrasoft soil under cyclic loading," Journal of Materials in Civil Engineering, vol. 28, no. 11, Article ID 04016135, 2016. 
[10] J. M. Mayoral, J. M. Pestana, and R. B. Seed, "Multi-directional cyclic $p-y$ curves for soft clays," Ocean Engineering, vol. 115, pp. 1-18, 2016.

[11] L. L. Gu, Z. Wang, Q. Huang, G. L. Ye, and F. Zhang, "Numerical investigation into ground treatment to mitigate the permanent train-induced deformation of pile-raft-soft soil system," Transportation Geotechnics, vol. 24, Article ID 100368, 2020.

[12] R. J. Mitchell and R. D. King, "Cyclic loading of an Ottawa area Champlain Sea clay," Canadian Geotechnical Journal, vol. 14, no. 1, pp. 52-63, 1977.

[13] M. Hyodo, Y. Yamamoto, and M. Sugiyama, "Undrained cyclic shear behaviour of normally consolidated clay subjected to initial static shear stress," Soils and Foundations, vol. 34, no. 4, pp. 1-11, 1994.

[14] G. G. Moses, S. N. Rao, and P. N. Rao, "Undrained strength behaviour of a cemented marine clay under monotonic and cyclic loading," Ocean Engineering, vol. 30, no. 4, pp. 1765-1789, 2003.

[15] A. Sakai, L. Samang, and N. Miura, "Partially-drained cyclic behavior and its application to the settlement of a low embankment road on silty-clay," Soils and Foundations, vol. 43, no. 1, pp. 33-46, 2003.

[16] M. T. Yılmaz, O. Pekcan, and B. S. Bakır, "Undrained cyclic shear and deformation behavior of silt-clay mixtures of Adapazar1, Turkey," Soil Dynamics and Earthquake Engineering, vol. 24, no. 7, pp. 497-507, 2004.

[17] Z. Wang, L. Gu, M. Shen, F. Zhang, G. Zhang, and X. Wang, "Shear stress relaxation behavior of rock discontinuities with different joint roughness coefficient and stress histories," Journal of Structural Geology, vol. 126, pp. 272-285, 2019.

[18] D. A. Sangrey, D. J. Henkel, and M. I. Esrig, "The effective stress response of a saturated clay soil to repeated loading," Canadian Geotechnical Journal, vol. 6, no. 3, pp. 241-252, 1969.

[19] D. C. Koutsoftas, "Effect of cyclic loads on undrained strength of two marine clays," Journal of the Geotechnical Engineering Division, vol. 104, no. 5, pp. 609-620, 1978.

[20] T. Matsui, H. Ohara, and T. Ito, "Cyclic stress-strain history and shear characteristics of clay," Journal of the Geotechnical Engineering Division, vol. 106, no. 10, pp. 1101-1120, 1980.

[21] C. Gu, J. Wang, Y. Cai, Z. Yang, and Y. Gao, "Undrained cyclic triaxial behavior of saturated clays under variable confining pressure," Soil Dynamics and Earthquake Engineering, vol. 40, pp. 118-128, 2012.

[22] A. F. L. Hyde and S. J. Ward, "A pore pressure and stability model for a silty clay under repeated loading," Géotechnique, vol. 35, no. 2, pp. 113-125, 1985.

[23] N. Matasović and M. Vucetic, "Generalized cyclic-degradation-pore-pressure generation model for clays," Journal of Geotechnical Engineering, vol. 121, no. 1, pp. 33-42, 1995.

[24] Y. Huang, Z. C. Chen, and H. B. Zhou, "Dynamic calculation model of Shanghai soft soil," Journal of Tongji University (Natural Science), vol. 28, no. 3, pp. 359-363, 2000, in Chinese.

[25] S. Ohara and H. Matsuda, "Study on the settlement of saturated clay layer induced by cyclic shear," Soils and Foundations, vol. 28, no. 3, pp. 103-113, 1988.

[26] M. Paul, R. B. Sahu, and G. Banerjee, "Undrained pore pressure prediction in clayey soil under cyclic loading," International Journal of Geomechanics, vol. 15, no. 5, Article ID 04014082, 2015.

[27] X.-W. Ren, Q. Xu, C.-B. Xu, J.-D. Teng, and S.-H. Lv, "Undrained pore pressure behavior of soft marine clay under long-term low cyclic loads," Ocean Engineering, vol. 150, pp. 60-68, 2018.

[28] D. C. Procter and J. H. Khaffaf, "Cyclic triaxial tests on remoulded clays," Journal of Geotechnical Engineering, vol. 110, no. 10, pp. 1431-1445, 1984.

[29] A. M. Ansal and A. Erken, "Undrained behavior of clay under cyclic shear stresses," Journal of Geotechnical Engineering, vol. 115, no. 7, pp. 968-983, 1989.

[30] A. F. L. Hyde, K. Yasuhara, and K. Hirao, "Stability criteria for marine clay under one-way cyclic loading," Journal of Geotechnical Engineering, vol. 119, no. 11, pp. 1771-1789, 1993.

[31] S. Araki, W. Kunimatsu, S. Nishiyama et al., "Experimental study on tsunami wave load acting on storage tank in coastal area," Journal of Loss Prevention in the Process Industries, vol. 50, pp. 347-354, 2016.

[32] H.-J. Park, J.-G. Ha, S.-Y. Kwon, M.-G. Lee, and D.-S. Kim, "Investigation of the dynamic behaviour of a storage tank with different foundation types focusing on the soil-foundationstructure interactions using centrifuge model tests," Earthquake Engineering \& Structural Dynamics, vol. 46, no. 14, pp. 2301-2316, 2017.

[33] ASTM D2487-17, Standard Practice for Classification of Soils for Engineering Purposes (Unified Soil Classification System), ASTM, West Conshocken, PA, USA, 2017.

[34] GB/T 50123-2019, Standard for Geotechnical Testing Method, Ministry of Water Resources of the People's Republic of China, China Planning Press, Beijing, China, 2019.

[35] J. Zhou and X. Gong, "Strain degradation of saturated clay under cyclic loading," Canadian Geotechnical Journal, vol. 38, no. 1, pp. 208-212, 2001.

[36] X. Cui, N. Zhang, J. Zhang, and Z. Gao, "In situ tests simulating traffic-load-induced settlement of alluvial silt subsoil," Soil Dynamics and Earthquake Engineering, vol. 58, pp. 10-20, 2014.

[37] W. Huang, K. J. Wen, D. S. Li et al., "Experiment study of lateral unloading stress path and excess pore water pressure on creep behavior of soft soil," Advances in Civil Engineering, vol. 2019, Article ID 9898031, 9 pages, 2019.

[38] L. Guo, J. Wang, Y. Cai, H. Liu, Y. Gao, and H. Sun, "Undrained deformation behavior of saturated soft clay under long-term cyclic loading," Soil Dynamics and Earthquake Engineering, vol. 50, pp. 28-37, 2013.

[39] P. H. Liu, H. G. Fang, and L. J. Song, "Experimental investigation for structural effect of soft clay under low frequency cyclic loading," Applied Mechanics and Materials, vol. 438439, pp. 673-676, 2013.

[40] ASTM D4767-11, Standard Test Method for Consolidated Undrained Triaxial Compression Test for Cohesive Soils, ASTM, West Conshocken, PA, USA, 2020.

[41] H. Matsuda, T. Thanh Nhan, and R. Ishikura, "Prediction of excess pore water pressure and post-cyclic settlement on soft clay induced by uni-directional and multi-directional cyclic shears as a function of strain path parameters," Soil Dynamics and Earthquake Engineering, vol. 49, pp. 75-88, 2013.

[42] C. Polito, R. A. Green, E. Dillon, and C. Sohn, "Effect of load shape on relationship between dissipated energy and residual excess pore pressure generation in cyclic triaxial tests," $\mathrm{Ca}$ nadian Geotechnical Journal, vol. 50, no. 11, pp. 1118-1128, 2013.

[43] G. Liu, M. Luan, X. Tang, Z. Wang, and Y. Guo, "Critical cyclic stress ratio of undisturbed saturated soft clay in the Yangtze estuary under complex stress conditions," Transactions of Tianjin University, vol. 16, no. 4, pp. 295-303, 2010. 
[44] J. K. Mitchell and K. Soga, Fundamentals of Soil Behavior, John Wiley and Sons, Inc., Hoboken, NJ, USA, 3rd edition, 2005.

[45] A. Puzrin, S. Frydman, and M. Talesnick, "Normalized nondegrading behavior of soft clay under cyclic simple shear loading," Journal of Geotechnical Engineering, vol. 121, no. 12, pp. 836-843, 1995.

[46] S. Soralump and J. Prasomsri, "Cyclic pore water pressure generation and stiffness degradation in compacted clays," Journal of Geotechnical and Geoenvironmental Engineering, vol. 142, no. 1, Article ID 04015060, 2015.

[47] D. Swartzendruber, "Modification of Darcy's law for the flow of water in soils," Soil Science, vol. 93, no. 1, pp. 22-29, 1962.

[48] Z. G. Xu, S. X. Feng, J. R. Chai et al., "The effect of initial shear stress of clay bound water on non-Darcy flow," Journal of Water Resources and Water Engineering, vol. 28, no. 6, pp. 200-208, 2017, in Chinese.

[49] J. H. Brewer, The response of cyclic stress in a normal consolidated saturated clay, Ph.D. thesis, North Carolina State University, Raleigh, NC, USA, 1972.

[50] X. P. Wang and J. Q. Wu, "Study on the variation regularity of shear strength of saturated soft clay under cyclic loading," Advanced Materials Research, vol. 250-253, no. 1-4, pp. 2388-2391, 2011.

[51] Z. Wang, M. Shen, W. Ding, B. Jang, and Q. Zhang, "Timedependent behavior of rough discontinuities under shearing conditions," Journal of Geophysics and Engineering, vol. 15, no. 1, pp. 51-61, 2018.

[52] Z. Wang, M. R. Shen, L. L. Gu, and F. Zhang, "Creep behavior and long-term strength characteristics of greenschist under different confining pressures," Geotechnical Testing Journal, vol. 41, no. 1, pp. 55-71, 2018.

[53] L. Guo, Y. Cai, R. J. Jardine, Z. Yang, and J. Wang, "Undrained behaviour of intact soft clay under cyclic paths that match vehicle loading conditions," Canadian Geotechnical Journal, vol. 55, no. 1, pp. 90-106, 2018.

[54] G. Mesri, A. Rokhsar, and B. F. Bohor, "Composition and compressibility of typical samples of Mexico City clay," Géotechnique, vol. 25, no. 3, pp. 527-554, 1975.

[55] G. G. Moses and S. N. Rao, "Behavior of marine clay subjected to cyclic loading with sustained shear stress," Marine Georesources and Geotechnology, vol. 25, no. 2, pp. 81-96, 2007.

[56] J. Ni, B. Indraratna, X. Y. Geng, and C. Rujikiatkamjorn, "The effect of the strain rate on soft soil behaviour under cyclic loading," in Proceedings of 11th Australia-New Zealand Conference on Geomechanics: Ground Engineering in a Changing World, pp. 1340-1345, Melbourne, Australia, July 2012.

[57] T. T. Nhan, H. Matsuda, and H. Sato, "A model for multidirectional cyclic shear-induced pore water pressure and settlement on clays," Bulletin of Earthquake Engineering, vol. 15, no. 7, pp. 2761-2784, 2017. 